\title{
DETERMINANTS OF THE ADOPTION OF INNOVATIVE FINTECH SERVICES BY MILLENNIALS
}

\section{Małgorzata Solarz', Magdalena Swacha-Lech²}

\footnotetext{
1 Wroclaw University of Economics and Business, Faculty of Economics and Finance, Department of Finance and Accounting, Poland, ORCID: 0000-0001-9538-0541, malgorzata.solarz@ue.wroc.pl;

2 Wroclaw University of Economics and Business, Faculty of Economics and Finance, Department of Finance, Poland, ORCID: 0000-0003-0129-2968, magdalena.swacha-lech@ue.wroc.pl.
}

\begin{abstract}
FinTech Adoption Index, expressed as a percentage of the digitally active population, for 27 countries of the world in 2019 reached the level of 64\%. Millennials are the generation which, compared to others, is characterized by the highest level of FinTech adoptions. In Poland, in 2019, about $75 \%$ of the Millennials used the services of FinTech. This paper aims to analyse and evaluate the selected determinants of using the innovative FinTech services by Millennials in Poland. To investigate how users adopt FinTech services, we have applied our own set of determinants - selected from an extensive literature review - covering both demographic, economic and behavioural characteristics. This approach allowed for an in-depth analysis of the examined issue. The essential empirical data were obtained based on the research using the CAWI method in December 2019 on a representative sample of Poles aged 25-40 at that time. Ultimately, 1,236 correctly completed questionnaires were used for the research. To analyse and evaluate the impact of selected determinants of FinTech adoption, a logistic regression model was used. The results obtained can thus be extremely important for managers of financial institutions. They provide information that can be used for activities aimed at maintaining FinTech's customer base and allow to adjust the offer to the expectations of this group. Millennials most open to innovative FinTech services in Poland are young men with high and very high net income and not driven by low costs of financial services. They appreciate technological novelties, including the possibility of using a smartwatch, and when deciding on the choice of a financial institution, they do not care about the direct opinions of their relatives and friends, but take into account the opinions in social media.
\end{abstract}

Keywords: FinTech, Millennials, determinants of using FinTech services, perceived benefit, FinTech adoption.

JEL Classification: G23, O33, D12, G21.

APA Style Citation: Solarz, M., \& Swacha-Lech, M. (2021). Determinants of the Adoption of Innovative FinTech Services by Millennials. E\&M Economics and Management, 24(3), 149-166. https://doi.org/10.15240/tul/001/2021-3-009

\section{Introduction}

According to the study by Ernst \& Young entitled: "Global FinTech Adoption Index 2019", the level of users taking advantage of FinTech services, expressed as a percentage of the digitally active population for 27 selected countries in 2019 presented the level of $64 \%$. It is worth pointing out that for China this figure amounted to $87 \%$, Great Britain $71 \%$,
Switzerland $64 \%$ and the USA 46\% (Ernst \& Young, 2019).

As highlighted by Anderson (2015), people of different generations and demographic backgrounds incorporate new technology into their lives at different rates. This paper is focused on Millennials alone, also referred to as Generation Y. This generation includes people born in the period from 1980 to 1995. Millennials, 
along with Generation Z (also known as iGen and referring to people born in the years 1996-2010), belong to the generations which currently generate highly significant changes in the environment of modern financial institutions (Swacha-Lech, 2019).

As evidenced by the results of the research conducted by Capgemini \& Efma (2016) covering 6 regions of the world, Millennials are more likely than other generations to use the services offered by FinTech. For example, it can be indicated that in Western Europe the adoption of FinTech among Millennials reached the level of $65.6 \%$, whereas for the other age groups it was $53.2 \%$. In Central Europe, the difference between the adoption of FinTech among the members of Millennials generation and the remaining generations was slightly lower - 9.5\% (the respective figures were $72.6 \%$ vs. $63.1 \%$ ). According to the results of the Ernst \& Young (2017) report, the FinTech Adoption Index for the Millennials generation in global terms was $48 \%$, while in the USA it was $59 \%$. In Poland, in 2019, this ratio for the Millennials generation was approximately $75 \%$ (Kurek et al., 2020).

The aim of this paper is to analyse and evaluate the impact of selected determinants on the adoption of innovative FinTech services by Millennials in Poland. In order to investigate how users adopt FinTech services, researchers focused on different sets of features. One of the approaches most frequently used for this purpose is applying the approach called TAM (Technology Acceptance Model), which is based on the two determinants: perceived usefulness and perceived ease of use (Davis, $1985,1989)$. This way of discussion is based on a behavioural perspective. Another approach towards analyzing this problem used by scientists, is focused on investigating the impact of various demographic, social and economic variables on the willingness to adopt FinTech services (Carlin et al., 2017; Das \& Das, 2020; $\mathrm{Li}$ et al., 2020). Still other solutions provided in the subject literature approach the analysed problem from the perspective of perceived risks (Diana \& Leon, 2020; Li et al., 2020; Ryu, 2018) or benefits (Diana \& Leon, 2020; Ryu, 2018) associated with using FinTech services, which are also related to behavioural finance. Many scientists combine the selected variables from the discussed approaches in order to analyse the determinants of using innovative
FinTech services in a more extensive context. Similarly, this paper is focused on the variables of a demographic (gender, age), economic (income) and behavioural (factors influencing decisions about the choice of a financial institution as well as perceived benefits) nature. The catalogue of benefits is broken down into the advantages: regarding the access channel to a particular FinTech service, related to a specific financial institution, and benefits resulting from a specific financial service. The selection of such a catalogue of variables allows taking a broad approach to the analysis of adopting FinTech by Millennials in Poland. To analyse and evaluate the impact of selected determinants of FinTech adoption, a logistic regression model was used.

The research results presented in the article are intended to contribute to the understanding of the FinTech problem from the customers' point of view, while the majority of publications on FinTech focus on the supply aspects. The analysis of the adoption rate of innovations is an issue that has been considered by many researchers, taking into account a variety of determinants. FinTech is a relatively new phenomenon in the financial market hence there is still a need for research that deepens the problem of FinTech adoption. This article also fills a gap in the area of in-depth research on the adoption of FinTech services across generations. Indeed, there is little research focusing on analyzing the broad determinants of FinTech adoption by Millennials (cf. Carlin et al., 2017). However, this generation is now a dominant part of the customers of financial institutions, so identifying their needs appears to be crucial from the point of view of these institutions.

\section{Theoretical Background 1.1 The Essence of FinTech}

The world literature does not offer one uniform approach to the FinTech concept. The etymology of this term was derived from the words "finance" (financial services) and "technology" (information technology) (Gimpel et al., 2018). The most general definitions, focusing on these two distinguished elements, show FinTech as products or services in financial service companies that were created on highly innovative and disruptive service technologies (European Parliament, 2017; Lee \& Teo, 2015; OECD, 2018). Moreover, many 
authors take the approach which emphasizes the ability of FinTech to generate additional benefits. In such case FinTech is considered as a technology enabler to provide a better user experience and improve competitiveness in finance (Tang et al., 2020). The example of defining FinTech in such a way is presented in the following definitions:

- FinTech refers to the use of emerging information technologies, including big data, cloud computing and mobile technologies, to improve the quality of services and management efficiency, and expand the field of financial services (Hu et al., 2019);

- technology-enabled innovation in financial services that could result in new business models, applications, processes or products with an associated material effect on the provision of financial services (Financial Stability Board, 2019);

- the advances in technology that have the potential to transform the provision of financial services spurring the development of new business models, applications, processes, and products (International Monetary Fund, 2018);

- the innovation and technology disruption of financial services by non-financial enterprises, with the help of FinTech, customers can participate in a variety of mobile environment services - e.g. online payment, fund transfer, loan application, purchase of insurance policies, management of organisational assets and management, stock investment, mobile payment, InsureTech, P2P lending, crowdfunding, cryptocurrency (Ryu, 2018).

\subsection{Technology Acceptance Models}

In 1980, Ajzen and Fishbein (1980) proposed the Theory of Reasoned Action (TRA) to study the elements affecting an individual's conduct when embracing specific technologies. Following this approach, the authors suggest that an individual's behavioural intention is a combination of their attitude toward behaviour and subjective norm factors (Stewart \& Jürjens, 2018). Basing on TRA, Davis (1985) proposed the Technology Acceptance Model (TAM), which is one of the most widespread approaches to analysing the adoption of new technologies. Two crucial determinants, which are used in the TAM model are: perceived usefulness - the degree to which a person believes that using a particular system would enhance his or her job performance and perceived ease of use - the degree to which a person believes that using a particular system would be free of effort (Davis, 1985, 1989). Research on the impact of both these determinants on the adoption of new technology in banking was conducted by Montazemi and Qahri-Saremi (2015) and Szopiński (2016). Among the scientists using TAM for research on FinTech we can mention Huei et al. (2018) and Nangin et al. (2020). In the course of subsequent studies, the model was extended with additional variables. It was also introduced: TAM 2 (Venkatesh \& Davis, 2000) and TAM 3 (Venkatesh \& Bella, 2008).

To investigate how users adopt FinTech services Hu et al. (2019) propose an improved TAM that includes: user innovativeness, government support, brand image, and perceived risk as determinants of trust. They proved that users' trust in FinTech services has a very significant influence on attitudes for adoption, while perceived ease of use and perceived risk does not affect it. Nangin et al. (2020) found that perceived ease of use had a positive effect on customer trust.

The TAM model also became the basis for the development by Venkatesh et al. (2003), the Unified Theory of Acceptance and Use of Technology (UTAUT). The UTAUT model is based on four key constructs: performance expectancy, effort expectancy, social influence and facilitating conditions. As Venkatesh et al. (2012) emphasize, these key constructs are theorized to influence behavioural intention to use technology, while behavioural intention and facilitating conditions affect technology use. The authors of the model define social influence as "the extent to which consumers perceive that important others (e.g., family and friends) believe they should use a particular technology". Many authors confirmed the key role of the influence of the surrounding social environment on customers' intention to adopt new technology in finance (Alalwan et al., 2017; Kim et al., 2016; Martins et al., 2014; Yu, 2012). Research on the influence of the opinion of friends or relatives on use FinTech to make donations, conducted by Niswah et al. (2019) proved that this factor has a positive effect on intention to use these institutions. It should be emphasized that in digital era, not only opinions expressed in direct contact, but also those expressed via the Internet, have a significant 
impact on shaping financial decisions. As Niswah et al. (2019) indicate, today we can publish content on the Internet, use social media and the public opinion can influence on our opinion and decision to do something.

Customer loyalty is another determinant that influences the adoption of FinTech. One of the important factors influencing customer loyalty is habit. The researchers who confirmed that habit positively affect the loyalty of clients of financial institutions include Lin and Wang (2006) and Yee and Faziharudean (2010). Habitual behavior comes down to the continuation of the same type of behavior and is not based on a thoughtful, rational decision-making process, but is guided by automated cognitive processes (Yee \& Faziharudean, 2010). Most habitual behavior arises and proceeds efficiently, effortlessly and unconsciously (Aarts et al., 1998).

\subsection{Perceived Risks and Benefit}

Another factor determining the adoption of new technologies is the level of risk perceived by the consumer. As emphasized by Tang et al. (2020), the theory of perceived risk is used to understand consumer behavior. The study conducted by Solarz and Swacha-Lech (2019) shows that risk aversion is a factor that significantly affects financial decisions. Research carried out by numerous authors (Liébana-Cabanillas et al., 2014; Wu \& Wang, 2005) proves that perceived risk is a barrier of the adoption of a new technology. Perceived risk is also an important determinant in the context of the adoption of FinTech services. $\mathrm{Wu}$ and Wang (2005) found a significant relationship between perceived risk and the intention to use mobile payments. $\mathrm{Li}$ et al. (2020) have confirmed that the likelihood of using mobile payments will increase with risk tolerance. Interesting research, examining the impact of broadly understood perceived risk on the intention to use FinTech, was carried out by Ryu (2018). The author investigated four major dimensions of perceived risk: financial, legal, security and operational risks. Ryu proved that perceived risk negatively affects the adoption of FinTech, while legal risk has the greatest negative impact. Tang et al. (2020) conducted similar studies and found that financial, legal as well as operational risk have a significant negative impact on the intention to use FinTech.

Few authors consider the perceived risk together with the perceived benefit (Diana
\& Leon, 2020; Ryu, 2018). Hu et al. (2019) noted that FinTech refers to the use of new technologies - including big data, cloud computing and mobile technologies - to improve the quality of services and management efficiency, and to expand the area of financial services. In this context, FinTech can be seen as a way to provide a better user experience and improve financial competitiveness (Tang et al., 2020). From the consumers' point of view, the benefits provided by FinTech allow them to gain an environment of amplification and transparency, reduce expenses, eliminate intermediaries, as well as make financial information more accessible (Zavolokina et al., 2016). Ryu (2018) distinguishes three major dimensions of perceived benefits: economic benefits, convenience and transaction process. The author defined perceived benefits as "a customers' perception of the potential that FinTech adoption will result in a positive outcome". The results of this study shows that perceived benefit positively affects the FinTech adoption.

As Lee and Teo (2015) pointed out, economic benefits are the best researched group of benefits associated with FinTech. Thanks to modern technologies, FinTech can lower transaction and capital costs than traditional financial service, enabling FinTechs' customers to achieve economic benefits. Carlin et al. (2017) proved that FinTech adoption reduces financial fee payments and penalties. They examined this issue through the prism of individual generations and proved that only Millennials and members of Generation X incur fewer financial fees and penalties.

Considering the benefits offered by FinTech, Ryu (2018) distinguished also convenience. Based on findings developed by Lee and Teo (2015), the author assumed that convenience is driven from portability and immediate accessibility, and refers to flexibility in time and location. He proved that convenience has the strongest positive effect on FinTech adoption. The last dimension of benefits introduced by Ryu - transaction process - refers to the transaction related benefits of using FinTech for their financial transactions (e.g., buying, money transferring, lending and investing). Seamless transactions, as characteristic of FinTech, allow customers to improve the speed of transactions as well as to increase their efficiency. The results of a global study of 500 senior banking 
and insurance conducted by Cognizant et al. (2016) allowed the authors to identify crucial challenges. Most of the indications were obtained accordingly: IoT - moving from price to value, wearables - payments on the go and full omni-channel integration.

Taking into account the determinants influencing the level of FinTech adoption, benefits related to a given financial institution should also be considered. Among this group it should be indicated: comprehensiveness of financial services as well as security offered by modern technologies. While banks combine many different activities and have an extensive scale and scope of activity, FinTech firms have more specialized business models forcing a disaggregation of the value chain (Boot, 2017). In Poland, the vast majority of banks are universal banks, offering a wide range of services, while the FinTech operating on the market focus only on a selected area of activity (e.g. only mobile payments).

The crucial feature of FinTech is providing technology-driven solutions in finance. Many modern technologies increase the sense of security from the point of view of FinTech customers. These solutions include, among others: public cloud infrastructure; Artificial Intelligence (Al) - cognitive computing and machine learning (virtual assistants, Robo-Advisory, e.g. in wealth management); distributed ledger technology (DLT), e.g. blockchain, biometrics, and identity management systems; e.g. finger vein or selfie pay (Swacha-Lech, 2019).

\subsection{Demographic and Economic Factors}

The next group of factors that determine the propensity to use new technologies are demographic factors. Many researchers point out that age is critical to adopting technology and is negatively related to technology acceptance (Anderson, 2015; Flavián et al., 2006; LiébanaCabanillas et al., 2014). Similar relationships are proven by the research results conducted by authors investigating the relationship between age and adoption of FinTech. Das and Das (2020) indicated that 66.6 and $62.3 \%$ of the people belonging to the age group 18-28 years and 29-39 years are regular users of FinTech services, whereas in the age category above 50 years there were only $26.9 \%$. Similarly, Li et al. (2020) found that younger consumers are more likely to adopt mobile payments than older consumers - the predicted likelihood of using mobile payments for an adult aged 20 is almost 10 times greater than that for an adult aged 75 .

Gender is another demographic determinant that influences the acceptance of new technologies. The research results show that men are more likely to adopt a new technology than women (Das \& Das, 2020; Flavián et al., 2006; Li et al., 2020; Morris et al., 2005). An interesting research on age was also conducted by Carlin et al. (2017). The authors examined gender differences in technology adoption by analysing a broader context, i.e. investigating the answer to the following question - how better access to financial information via new technology changes the use of consumer credit and affects financial fitness. The results of the conducted research show that men tend to adopt new technology and access information at a higher rate, but the economic impact of access is larger for women - each added login in a smartphone application lowered bank fees by 238.1 kronor $(\$ 1.98)$ for women and by 195.2 kronor (\$1.63) for men.

Far fewer studies confirm the link between the propensity to adopt innovation and education. The research conducted by Rogers (2010), in the context of technology adoption, shows that early adopters can adopt an innovation because of higher education level. This relationship was also analysed by Szopiński (2016), who proved that the level of education of the respondents positively influences the use of online banking. The research conducted by Li et al. (2020) partially supported the hypothesis that the likelihood of using mobile payments will increase along with education level. The authors proved that the respondents with post-bachelor degree had a higher predicted rate than those with a high school or lower degree $(27 \%$ vs. $22 \%)$, though there were not monotonic increases in the likelihood of use with education. A positive correlation between the level of education and the adoption of FinTech services has also been confirmed in the research conducted by Das and Das (2020).

Similarly, only few of the conducted studies prove the income level impact on the acceptance of technological innovations. Research related to the impact of income on the use of online banking carried out by Flavián et al. (2006) shows that this factor has a significant impact on the level of adoption of online banking services 


\section{Finance}

(person with an annual income of over 36,000 euros was more likely to conduct transactions over the internet than someone with an income of between 24,000 and 36,000 euros per year). Due to the fact that the perceived cost is a significant barrier affecting the acceptance level of mobile payments (Mallat, 2007; Wu \& Wang, 2005), it seems correct to assume that the earned income is the determinant of using innovative mobile payments. However, the results of empirical research conducted in this context by Li et al. (2020) only partially support the assumption made by the authors that the likelihood of using mobile payments will increase with income, because there were not monotonic increases in the likelihood. Das and
Das (2020) proved that the adoption of FinTech services depends on the income of customers.

The research results presented in this part of the article became the basis for the formulation of research hypotheses.

\section{Research Methodology}

The research was conducted using the CAWI method in December 2019 by SW Research agency on a representative sample of Polish Millennials aged $25-40$ at that time. The research sample was selected in a random and quota manner (Blair \& Blair, 2015; Park \& Lee, 2006; Sirken, 2002). The structure of the sample was corrected using analytical weight, so that it corresponded to

\section{Tab. 1: The characteristics of the research sample}

\begin{tabular}{|c|c|}
\hline Research criterion & Percentage of the respondents \\
\hline \multicolumn{2}{|l|}{ Gender: } \\
\hline - women & $58.18 \%$ \\
\hline - men & $41.82 \%$ \\
\hline \multicolumn{2}{|l|}{ Age: } \\
\hline - $25-30$ & $42.56 \%$ \\
\hline - $\quad 31-35$ & $26.78 \%$ \\
\hline - $\quad 36-40$ & $30.66 \%$ \\
\hline \multicolumn{2}{|l|}{ Education: } \\
\hline - primary, lower secondary or vocational education & $8.50 \%$ \\
\hline - secondary education & $36.32 \%$ \\
\hline - higher education & $55.18 \%$ \\
\hline \multicolumn{2}{|l|}{ Monthly personal net income (in PLN): } \\
\hline - no income & $4.73 \%$ \\
\hline - below 500 & $12.00 \%$ \\
\hline - $\quad 501-1,500$ & $2.91 \%$ \\
\hline - $1,501-2,000$ & $35.18 \%$ \\
\hline - $2,001-3,000$ & $16.09 \%$ \\
\hline - $3,001-4,000$ & $9.45 \%$ \\
\hline - $4,001-5,000$ & $4.36 \%$ \\
\hline - $5,001-6,000$ & $2.91 \%$ \\
\hline - $6,001-7,000$ & $4.36 \%$ \\
\hline - $7,001-8,000$ & $2.91 \%$ \\
\hline - $8,001-9,000$ & $2.91 \%$ \\
\hline - more than 9,000 & $6.00 \%$ \\
\hline
\end{tabular}


the structure of Millennials in Poland in terms of key characteristics related to the subject of the study. The weight construction process took into account such socio-demographic variables as gender, age, education level, and size of the town of residence. The response rate was at the level $98.6 \%$. 1,236 correctly completed questionnaires were accepted for further analysis. The unit of analysis in our research is an individual who uses innovative FinTech services belonging to the Millennials generation.

In research on the analysis of the impact of various determinants on the level of adoption of innovative technologies, the most commonly used methods are regression modeling and structural equation modeling. In this paper, a logistic regression model is used.

Using innovative services offered by FinTech is the dependent variable, where 1 was assigned to Millennials who used FinTech, and 0
- to those who did not. The dependent variable is therefore a dichotomous variable. Logistic regression is a statistical model that uses a logistic function to model a binary dependent variable, making it ideal for analyzing the results of the research we designed. The results of the conducted research indicate that $74.76 \%$ of the surveyed population used the FinTech offer at least once, thus $25.24 \%$ of the respondents have not done it so far.

Tab. 1 describes the research sample considering gender, age, education level and personal income.

Taking into account the conclusions of the theoretical background, presented in the previous point of the article, we propose thirteen research hypotheses. Fig. 1 presented analytical framework for the research model.

The first three hypotheses are related to the determinants that have been assigned to the group of factors influencing the decisions about

\section{Fig. 1: Research model}

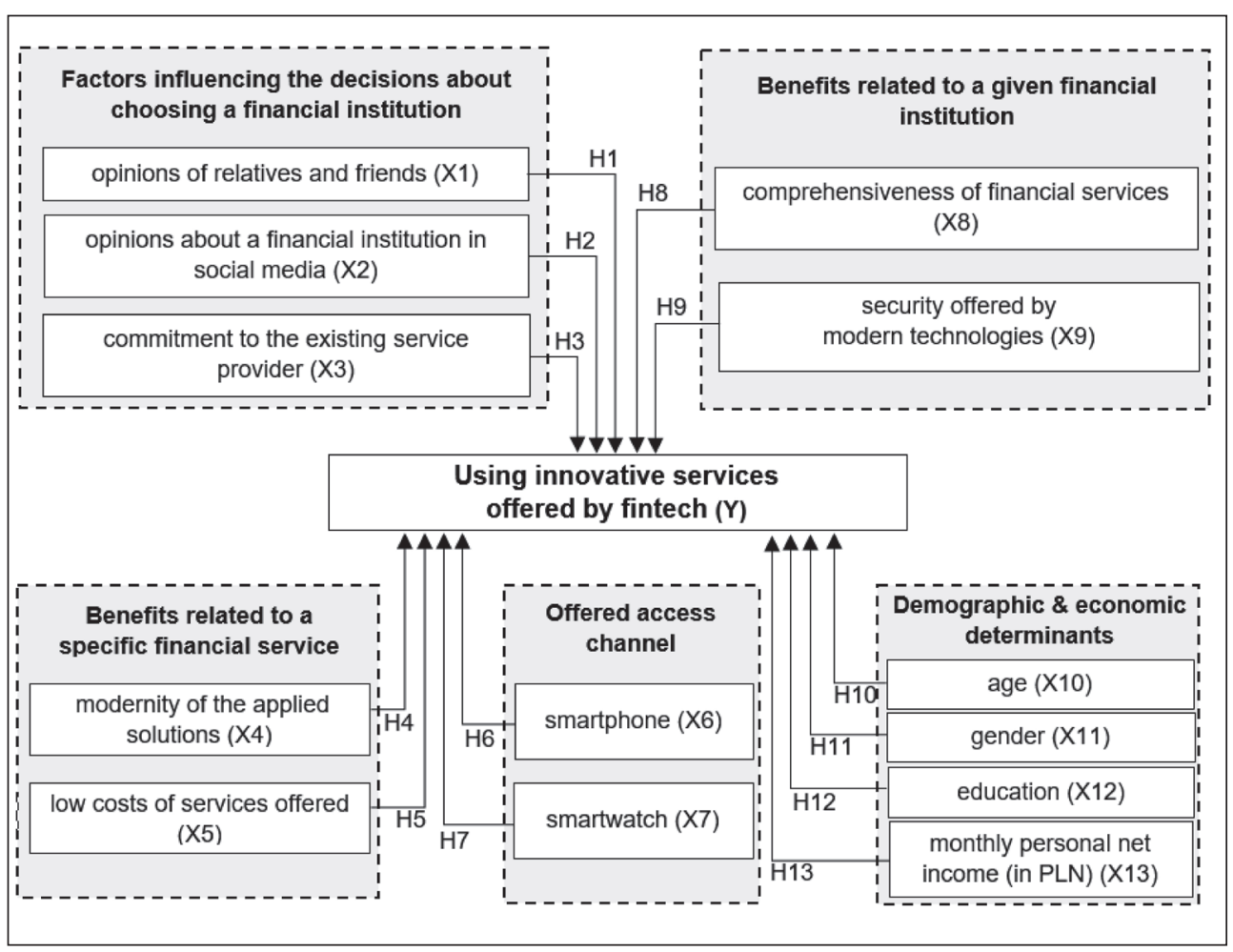


choosing a financial institution. In line with the observations that the social environment plays a key role for the adoption of new technologies in finance (Alalwan et al., 2017; Kim et al., 2016; Martins et al., 2014; Niswah et al., 2019; Yu, 2012), we suggest the following hypotheses:

H1: Using innovative services offered by FinTech is more likely for Millennials who make decisions about choosing a financial institution based on the direct opinions of relatives and friends, comparing to those who consider these opinions irrelevant.

H2: Using innovative services offered by FinTech is more likely for Millennials who make decisions about choosing a financial institution based on the opinions about a financial institution in social media, comparing to those who do not do it.

In this article, the customer's commitment to a financial institution is understood as using several services from the same institution, guided by habit. As Lin and Wang (2006) and Yee and Faziharudean (2010) proved, habit positively affects customer loyalty of financial institutions. A well-entrenched habit makes people tend to ignore external information or rational strategy (Lin \& Wang, 2006). The proposed $H 3$ is based on the assumption that clients who are loyal to traditional financial institutions use FinTech less frequently:

H3: Using innovative services offered by FinTech is less likely for Millennials who make decisions about choosing a financial institution based on commitment to the existing service provider, comparing to those who do not do it.

Further hypotheses relate to the advantages offered by FinTech. As proved Ryu (2018), perceived benefits positively affect FinTech adoption. In this article we have created three groups of benefits (Fig. 1). Benefits for clients related to a specific financial service include: modernity of applied solutions and low costs of offered services (Carlin et al., 2017; Lee \& Teo, 2015). Based on the questions (using the 4-point Likert scale) included in the questionnaire, we obtained information about the importance of both of these features for the respondents making the decision to use the services of a given financial institution. Therefore, we propose the following hypotheses:

H4: The likelihood of using innovative services offered by FinTech will decrease along with the decline in the importance of modernity of the applied solutions for Millennials.
H5: The likelihood of using innovative services offered by FinTech will decrease along with the decline in the importance of low costs of offered services for Millennials.

Taking into account the results of the study conducted by Ryu (2018) that convenience has the strongest positive effect on FinTech adoption, we have distinguished a group of benefits for the client related to the access channel offered. In line with the assumption that people open to various technological innovations are more likely to use innovations in finance, we propose the following hypotheses:

H6: Using innovative services offered by FinTech is more likely for Millennials for whom the possibility of using a smartphone is important, comparing to those for whom the possibility of using this type of technology is not important.

H7: Using innovative services offered by FinTech is more likely for Millennials for whom the possibility of using a smartwatch is important, comparing to those for whom the possibility of using this type of technology is not important.

Both of the distinguished benefits are in fact objective (a financial institution has the possibility to use access to a given service via smartphone/smartwatch or not), therefore the subjective feeling of the respondent related to the importance of a given benefit for his choice concerning the use of FinTech was analysed.

The last group of distinguished advantages is benefits related to a given financial institution. On the basis of research conducted by Boot (2017) and Swacha-Lech (2019) concerning the specificity of the functioning of the FinTech and technologies used by them, we propose the following hypotheses:

H8: Using innovative services offered by FinTech is more likely for Millennials for whom the comprehensiveness of financial services is not important, comparing to those for whom this benefit is important.

H9: Using innovative services offered by FinTech is more likely for Millennials for whom the security offered by modern technologies is important, comparing to those for whom this benefit is not important.

The last group of determinants influencing the adoption of FinTech by Millennials in Fig. 1 are demographic and economic factors. Investigations carried out by researchers clearly indicates that age is very important to 
the adoption of technology and is negatively related to technology acceptance (Anderson, 2015; Das \& Das, 2020; Flavián et al., 2006; Li et al., 2020; Liébana-Cabanillas et al., 2014). Therefore, we suggest the following hypothesis:

H10: The likelihood of using of innovative services offered by FinTech will decrease with age.

Similarly, studies related to gender indicate unequivocally that men are more likely to adopt a new technology than women (Carlin et al., 2017; Das \& Das 2020; Flavián et al., 2006; Li et al., 2020; Morris et al., 2005). Taking into account these observations, we propose $H 11$ :

H11: Males are more likely to use of innovative services offered by FinTech than females.

H12 is based on the results of research confirming the existence of a positive correlation between the level of education and the propensity to adopt new technologies. Among the researchers who proved this regularity, the following should be indicated: Rogers (2010), Szopiński (2016) as well as Das and Das (2020).

H12: The likelihood of using of innovative services offered by FinTech will increase with education level.

Many studies confirm the significant influence of income on using of innovative technologies, among others Flavián et al. (2006), Mallat (2007), Wu and Wang (2005). Based on the results of the research carried out by Das and Das (2020) for FinTech, in this article we adopt the following hypothesis:

H13: The likelihood of using innovative services offered by FinTech increase with monthly net income.

A logistic regression model was used to analyse the effects of the variables presented in Fig. 1 on the dependent variable.

\section{Results}

The logistic regression model should be verified in the following areas: quality of the fit, significance of individual hypotheses and predictive power of the theory. The C-Pearson method and Spearman's rank method were used to study the correlation, adopting the significance coefficient at the level of $p<0.05$. The variables that were most strongly correlated with the dependent variable and, at the same time, weakly correlated with each other were adopted for modelling.

The results of three consecutive quality tests of the logistic regression model fit are presented in Tab. 2.

$G$ statistics for model deviance amounts to $1,372.266$ and is statistically significant. Therefore $\mathrm{HO}$ can be rejected and allow adopting that the model is definitely better than the random one. The second - HosmerLemeshow (1980) test result also confirms good model adjustment as it remains insignificant. The determination coefficient R2 Nagelkerke shows that $18.8 \%$ of the dependent variable variance is explained by the independent variables' variance. It proves the existence of variance percentage explained by other predictors absent in the model. To sum up, the theory confirmed the adjustment quality being better than the random model and providing a new explanation for the dependent variable behaviour.

After performing the model fit quality test, the hypothesis can be verified. Tab. 3 shows the logistic regression results.

The results of logistic regression prove that in contrast to the other variables, the variables $\mathrm{X} 3, \mathrm{X} 6, \mathrm{X} 8, \mathrm{X} 9, \mathrm{X} 12$ do not have a statistically significant influence on the use of innovative services offered by FinTech. Having analysed

\section{Tab. 2: The model's goodness-of-fit coefficients}

\begin{tabular}{l|l}
\multicolumn{1}{c|}{ Test } & \multicolumn{1}{c}{ Coefficient } \\
\hline \multirow{2}{*}{ Likelihood ratio test } & $-2 \log (\mathrm{L})=1,372.266$ \\
\cline { 2 - 2 } & $\operatorname{chi2}=171.067(\mathrm{df}=36 ; \mathrm{p}<0.000001)$ \\
\hline Hosmer-Lemenshow test & $\operatorname{chi} 2=12,577(\mathrm{df}=8 ; \mathrm{p}=0.127)$ \\
\hline $\mathrm{R}^{2}$ Nagelkerke & 0.188 \\
\hline
\end{tabular}




\begin{tabular}{l|c|c|c|c|c|c}
\multicolumn{1}{c|}{ Variables } & B & SE & OR & Wald & P \\
\hline Constant & 0.616 & 1.071 & 1.851 & 0.330 & \\
\hline \multicolumn{5}{l|}{ Factors influencing the decisions about choosing a financial institution } \\
\hline - $\quad$ opinions of relatives and friends (X1) & -0.440 & 0.141 & 0.644 & 9.770 & $*$ \\
\hline $\begin{array}{l}\text { opinions about a financial institution in social } \\
\text { media (X2) }\end{array}$ & 0.411 & 0.166 & 1.508 & 6.124 & $*$ \\
\hline - commitment to the existing service provider (X3) & -0.054 & 0.158 & 0.948 & 0.115 & \\
\hline
\end{tabular}

Benefits related to a specific financial service (ref: very important)

- modernity of the applied solutions (X4)

\begin{tabular}{ll}
\hline- & important \\
\hline- & unimportant \\
\hline- & totally irrelevant \\
\hline - & low costs of services \\
\hline- & important \\
\hline- & unimportant \\
\hline- & totally irrelevant
\end{tabular}

\begin{tabular}{|r|r|r|r|c} 
& & & 18.562 & $* * *$ \\
\hline-0.596 & 0.176 & 0.551 & 11.476 & $* *$ \\
\hline-1.110 & 0.502 & 0.330 & 4.898 & $*$ \\
\hline 0.434 & 0.156 & 1.543 & 7.722 & $* *$ \\
\hline 0.978 & 0.232 & 2.659 & 17.753 & $* * *$ \\
\hline 0.834 & 0.417 & 2.302 & 4.004 & $*$ \\
\hline
\end{tabular}

Offered access channel

\begin{tabular}{|c|c|c|c|c|c|}
\hline - smartphone (X6) & 0.181 & 0.150 & 1.199 & 1.458 & \\
\hline - $\quad$ smartwatch (X7) & 0.408 & 0.171 & 1.503 & 5.678 & * \\
\hline \multicolumn{6}{|l|}{ Benefits related to a given financial institution } \\
\hline - comprehensiveness of financial services $(X 8)$ & -0.265 & 0.145 & 0.767 & 3.374 & \\
\hline $\begin{array}{l}\text { - } \quad \text { security offered by modern technologies } \\
\text { (e.g. biometrics, blockchain) (X9) }\end{array}$ & 0.048 & 0.144 & 1.049 & 0.109 & \\
\hline \multicolumn{6}{|l|}{ Demographic and economic determinants } \\
\hline - $\quad$ age $(\mathrm{X} 10)$ & -0.059 & 0.015 & 0.943 & 14.859 & *** \\
\hline - $\quad$ gender (ref. women) (X11) & & & & 4.459 & * \\
\hline - men & 0.291 & 0.138 & 1.338 & 4.459 & * \\
\hline - education (ref. primary) (X12) & & & & 17.620 & * \\
\hline - lower secondary school & -0.429 & 1.110 & 0.651 & 0.149 & \\
\hline - basic vocational & -0.049 & 0.857 & 0.952 & 0.003 & \\
\hline $\begin{array}{l}\text { - incomplete secondary (secondary school } \\
\text { graduation without taking the final graduation } \\
\text { exam) }\end{array}$ & -0.724 & 0.862 & 0.485 & 0.705 & \\
\hline - general secondary & -0.318 & 0.806 & 0.728 & 0.155 & \\
\hline - $\quad$ secondary vocational & -0.210 & 0.809 & 0.811 & 0.067 & \\
\hline - post-secondary/college & -0.354 & 0.819 & 0.702 & 0.187 & \\
\hline $\begin{array}{l}\text { incomplete higher education (completed } \\
\text { university studies without the graduation } \\
\text { diploma) }\end{array}$ & 1.213 & 0.941 & 3.363 & 1.660 & \\
\hline _ bachelor's/engineering degree & -0.424 & 0.803 & 0.655 & 0.279 & \\
\hline
\end{tabular}




\section{Tab. 3: Logistic regressions' results - Part 2}

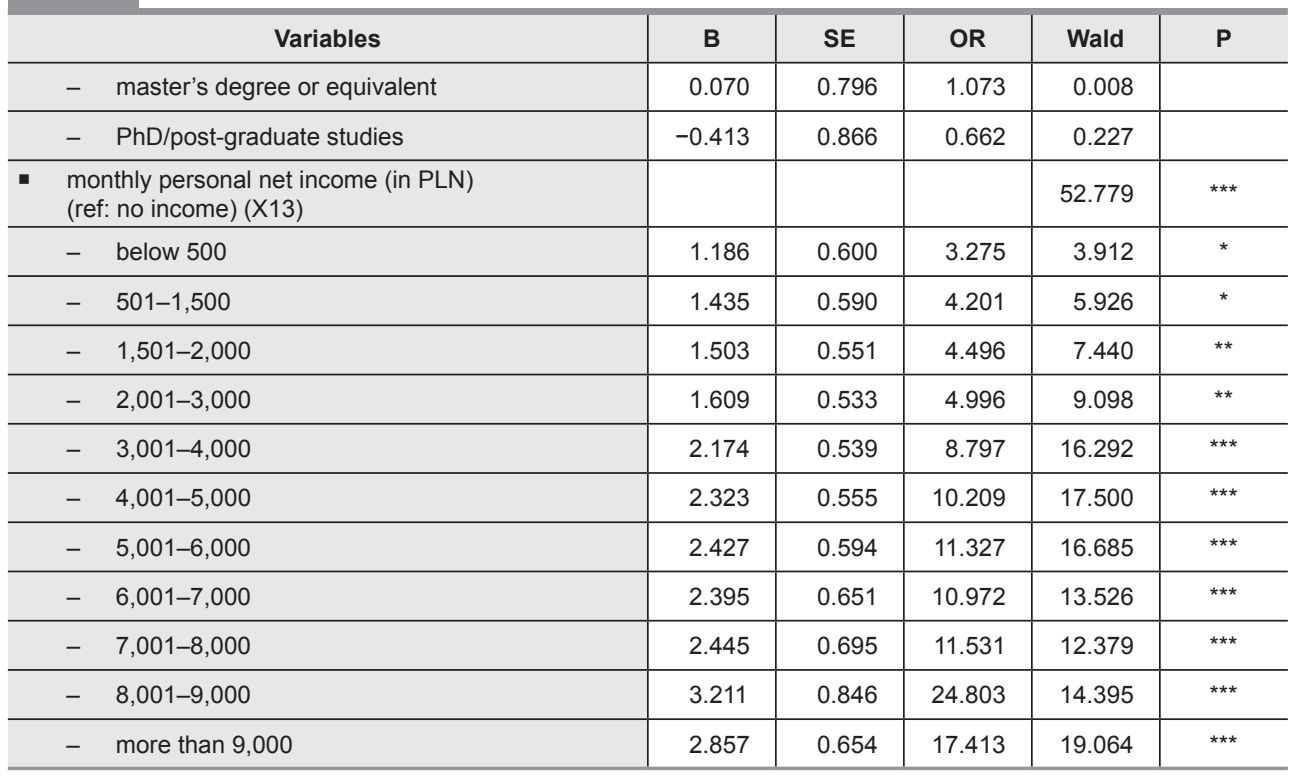

the odds ratios (Tab. 3), it can be concluded that the likelihood of using innovative FinTech services is as follows:

- $35.6 \%$ lower than in the case of Millennials who decide to choose a financial institution guided by the opinions of relatives and friends (X1) comparing to those who consider these opinions irrelevant;

- more than 1.5 times (1.508) higher for Millennials who choose a financial institution based on the opinions about it presented in social media (X2), comparing to those who do not do it;

- decreases along with the decline in the importance of the benefits resulting from using a specific financial service and relating to the modernity of the applied solutions (X4). E.g., for Millennials for whom modern solutions are important it is $44.9 \%$ lower than for those declaring that this parameter is very important; in turn, for those for whom the benefits of modern solutions are completely unimportant, it is as much as $67 \%$ lower comparing to those for whom they are very important;

- higher for Millennials for whom the low cost benefits of using a financial service (X5) are less than very important. E.g., for Millennials for whom low costs of offered services are important it is over 1.5 times (1.534) higher than for Millennials declaring that this parameter is very important; whereas for those who consider low costs associated with using the offer of little importance it is approx. 2.5 times (2.659) higher comparing to those for whom they are very important;

- over $150 \%$ (1.503) higher in relation to Millennials for whom the possibility of using a smartwatch (X7) is important, comparing to those for whom the possibility of using this type of technology is not important;

- $5.7 \%$ lower as the age (X10) of the given person (potential user) goes up by a year;

- almost 1.5 times (1.338) higher for men than for women (gender - X11);

- higher for Millennials who earn income as compared to those who declare no income (X13), and e.g. for Millennials whose monthly net income ranges from PLN 501 to PLN 1,500 it is more than 3 times (3.275) higher than for Millennials without income; in turn, as much as 10 times (10.209) higher for Millennials whose monthly net income remains within the range of PLN 
Tab. 4: Classification

\begin{tabular}{|c|c|c|c|c|}
\hline \multirow{2}{*}{\multicolumn{2}{|c|}{ Classification }} & \multicolumn{3}{|c|}{ Observed value } \\
\hline & & \multirow{2}{*}{$\begin{array}{c}0 \\
216\end{array}$} & \multirow{2}{*}{$\begin{array}{c}1 \\
113 \\
\end{array}$} & \multirow{2}{*}{$\begin{array}{c}\boldsymbol{\Sigma} \\
329\end{array}$} \\
\hline \multirow{3}{*}{ Predicted value } & 0 & & & \\
\hline & 1 & 253 & 557 & 810 \\
\hline & $\Sigma$ & 469 & 670 & 1,139 \\
\hline
\end{tabular}

Source: own

4,001-5,000 and as much as 25 times (24.803) higher for Millennials whose incomes range between PLN 8,001-9,000 comparing to those who do not have any income.

The next step relates to analysis of the model predictive power can be carried out. Tab. 4 shows the classification capacity of the theory. The effectiveness of the decision rule (ACC) amounts to $67.87 \%$ and is higher compared to the model with the intercept only, which means that it has an added value. The other factors, i.e. sensitivity $(C)$ and specificity $(S)$ are respectively: $C=83.13 \%$ and $S=46.06 \%$.

Thus, the model correctly classified approximately $68 \%$ of the decision classes, where $83 \%$ stand for the positive and correctly grouped cases, with $46 \%$ of the negative cases. It can, therefore, be observed that while the theory is capable of predicting the determinants of using innovative FinTech services correctly, it is slightly worse at predicting behaviours towards people who are not willing to use this type of services.

Based on the sensitivity and specificity, the ROC curve was developed. The area under the curve (AUC) was 0.707, which means that it is larger than 0.5 and thus the model is a good one as it classifies cases better than the random model.

\section{Discussion}

In this article we have assumed that using of innovative services offered by FinTech is more for Millennials who make their decisions about choosing a financial institution based on the direct opinions of relatives and friends $(H 1)$ and opinions about the financial institution found in social media (H2) comparing to those for whom these opinions are irrelevant. The results are consistent with the assumptions of UTAUT, which implies that social influence has a significant impact on the use of new technologies, as well as with the results of research conducted by Alalwan et al. (2017), Kim et al. (2016), Martins et al. (2014), Venkatesh et al. (2012), and $\mathrm{Yu}$ (2012). Considering the direction of influence of direct opinions of friends or relatives on the use of FinTech, the results of our research show that this factor has a negative impact on the likelihood of using FinTech services by Millennials. Niswah et al. (2019), in turn, showed that this factor has a positive effect on the intention to use FinTech. However, our survey results did not support this relationship. Only 436 out of 1,236 respondents $(35.28 \%)$ indicated that they are guided by the opinions of relatives and friends when choosing a financial service. A more detailed analysis of these responses shows that the $25-30$ age group (the youngest of the surveyed Millennials) has the highest number of such responses $45.41 \%$, while for the $31-35$ age group it is $30.50 \%$ and for the $36-40$ age group $-24.09 \%$.

A study conducted by Singh et al. (2020) demonstrates that social influence shows a significant negative impact on actual FinTech usage. The authors note, following Venkatesh et al. (2003), that the higher the age of the respondents, the less influence the environment has on their financial choices. While the very young are often strongly influenced by the advice and opinions of family or peer pressure, the increase in knowledge and experience gained with age reduces the role of social influence. As indicated by these authors, the opinion of social group discourages Millennials from using FinTech because they are more influenced by negative opinions than positive ones. That is, driven by opinions in which users of FinTech services indicate that these services are troublesome, fraud or a security threat, respondents are not likely to use FinTech.

In the case of $H 2$, the results of our research are in line with the adopted assumptions, 
showing that the Millennials, who are guided by opinions from social media, are more likely to use FinTech when deciding on the choice of a financial institution. Opinions about a financial institution in social media are nowadays an important source of information, which also influences financial decisions made by Millennials. The results of our study show that only $21.36 \%$ of respondents indicated that these opinions influence their choice of financial institution. The assumption about Millennials' tendency to base their decisions on opinions found on social media formed the basis for the considerations in the article Endsley et al. (2020). The purpose of the study is to understand Millennials and how to use social media to sell to them as well as to create a marketing plan targeting this age group in order to bring business to Ascend Federal Credit Union. One of the issues addressed in the study is to demonstrate the role of social media in decision-making. The results show that over $50 \%$ answered a 4 or a 5 on a scale of 1 to 7 , which, according to the authors, confirms that most of the respondents see these media as an influencing factor in some of their decisions in day-to-day life. The platform on which respondents spent the most hours was Instagram, followed by Facebook and YouTube. When asked if social media is a reliable place to find a business, over $77.4 \%$ of respondents said yes (definitely yes and probably yes).

Two further hypotheses were based on the assumption that the likelihood of using innovative services offered by FinTech decreases along with the decline in the importance of the following features of financial services: modernity of applied solutions $(\mathrm{H} 4)$ and low costs $(H 5)$. The crucial feature of FinTech is the use of new technologies in finance, so the direction of their impact on the adoption of FinTech firms seems obvious. The adopted assumption turned out to be appropriate for the Millennials in Poland. The results confirmed that people who appreciate modern solutions are more open to using innovative FinTech services. However, the situation is different with regard to the assumption of low costs associated with financial services. Lee and Teo (2015) indicated that modern technologies allow achieving economic benefit for customers, as confirmed by research conducted for the Millennials by Carlin et al. (2017). However, the study results for the Millennials in Poland are not consistent with these findings and do not confirm the assumption that those who value lower costs are more willing to use FinTech. It seems that this may be related to the level of monthly net income. For the respondents whose income is between 501-1,500 PLN, the likelihood of using innovative services offered by FinTech is more than three times higher than for Millennials without income and as much as 25 times higher for people with income between 8,001-9,000 PLN compared to those with no income. Thus, it can be assumed that the amount of costs connected with financial services is insignificant for people with high and very high incomes. The results require further research to determine whether the Millennials in Poland perceive FinTech as institutions offering services at lower costs than traditional financial institutions and whether FinTech adoption actually reduces financial fee payments and penalties among Polish Millennials.

In this study, we have assumed that Millennials guided by the use of smartwatch are more open to the use of innovative services offered by FinTech (H7). The use of smartwatches, which enable "payments on the go", is one of the manifestations of FinTech's innovation. Ryu (2018) identified convenience as a factor related to portability and immediate accessibility, providing consumers with flexibility in time and location. The author proved that convenience has a positive effect on FinTech adoption. Results of our research are in line with this study, showing that the more important is the possibility to use smartwatch when choosing a financial institution, the greater is the Millennials' tendency to use innovative FinTech services.

The demographic variables that have a statistically significant influence on using of innovative FinTech services by Millennials include age and gender. Our results are consistent with those of authors such as: Carlin et al. (2017), Das and Das (2020), Li et al. (2020), and Liébana-Cabanillas et al. (2014). Both of these hypotheses have been clearly confirmed. The first one is "the likelihood of using innovative services offered by FinTech decrease with age" (H10). In their case, the probability of using of innovative services offered by FinTech decreases by $5.7 \%$ as the age of a given respondent increases by one year. While for a 25 -year-old, the probability of using FinTech is $64 \%$, for a 15 -year-old, it 


\section{Fig. 2: The likelihood of using innovative services offered by FinTech}

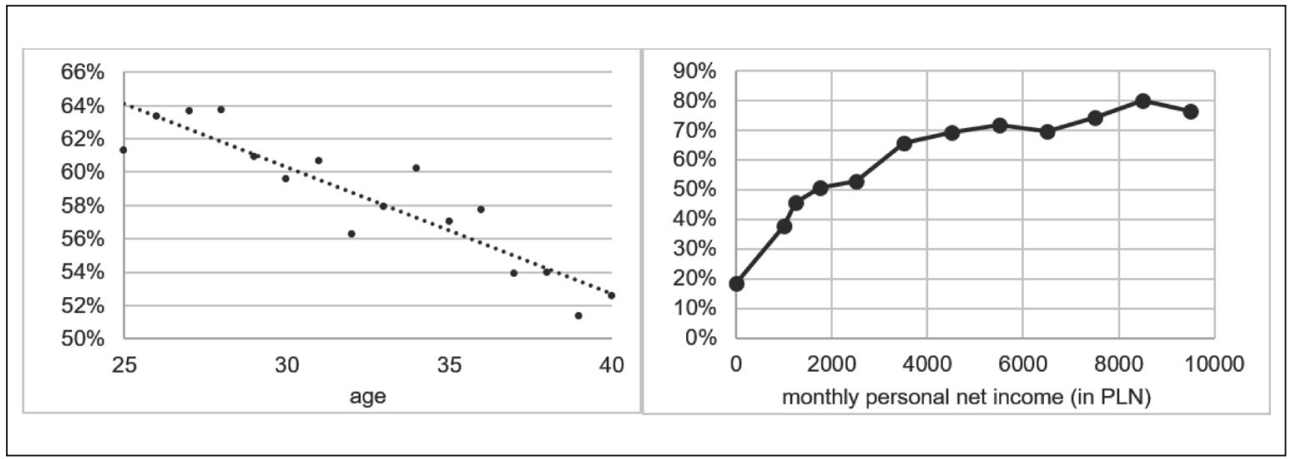

Source: own

is only about $53 \%$ (see Fig. 2). Thus, younger people are more open to modern technologies. As Hanna and Kim (2020) argue, it is possible that older generations tend to be anxious when trying to learn to use mobile payments, associated with lower perceived ease of use. With regard to gender, our research proves that males are more likely to use innovative services offered by FinTech than females (H11).

As shown in Fig. 2, the trend is upward, but no monotonic increases in the likelihood are observed. Similarly, the results of empirical studies conducted by Li et al. (2020) partially confirmed the assumption that the likelihood of using mobile payments increases with income. The authors point out, that households in higher income had somewhat higher likelihoods than those in lower income, but the pattern was not consistent.

To summarize the survey we conducted, we found support for the following hypotheses: $\mathrm{H} 2$, $H 4, H 7, H 10, H 11$, and only partially supported H13. Research conducted provides no support for $\mathrm{H} 1$ and $H 5$.

\section{Conclusions}

Recently, significant changes in the environment of financial institutions have been generated both by new, increasingly sophisticated technologies and by the changing expectations raised by new generations of customers. In this article, we have made a comprehensive review of the determinants of using innovative services offered by FinTech. Our research is based on a combination of factors of behavioural, social, economic and demographic nature. Conducted research explains and predict the adoption of FinTech services by Millennials in Poland.

With the emergence of FinTech on the financial market, more studies containing analyses related to the functioning of these entities began to appear in the literature, with most of the papers showing this issue from the supply side. Next, analyses from the demand side started to appear. Our article fits into this second, newer approach. The feature of this article is also the focus on one generation only. The Millennials is the generation that covers the years 1980 to 1995, and thus currently creates a wave of clients of great importance to financial institutions.

The results of research conducted in this paper provide information on the impact of broad-based determinants on FinTech adoption, thus making it possible to determine the characteristics of Millennials most open to the use of innovative FinTech services. These results can therefore be extremely important for managers of financial institutions. Millennials most open to FinTech services in Poland are young men with high and very high net income and not driven by low costs of financial services. They appreciate technological novelties, including the possibility of using a smartwatch, and when deciding on the choice of a financial institution, they do not care about the direct opinions of their relatives and friends, but take into account the opinions in social media.

Therefore, these results bring with them information that can be used for activities 
aimed at maintaining FinTech's customer base and allow to adjust the offer to the expectations of this group. On the other hand, our research shows which Millennials group does not yet use FinTech, allowing identifying the reasons for such decisions. On this basis, managers of individual financial institutions can take action to expand their customer base. We found serious indications for this that in Poland, the examined market will develop dynamically in the near future. Among the 312 Millennials who have not yet used FinTech: 97 respondents intend to use FinTech services within six months, and 131 respondents declared their intention to use them in further future.

The limitations include model's goodness of fit coefficients. A higher value would guarantee a higher level of model fit. Our research reveals a wide range of variables, but does not cover the perceived risk, which is also an important determinant of FinTech adoption. Inclusion of perceived risk in the analysis would provide an opportunity to confront perceived benefit and perceived risk. It seems that it would be interesting to expand the group of respondents and conduct research also for the youngest generation, Generation Z. Members of this generation, entering into adult life, will increasingly become clients of financial institutions.

Acknowledgment: The project is financed by the Ministry of Science and Higher Education in Poland under the program "Regional Initiative of Excellence" 2019-2022, project number 015/RID/2018/19, total funding amount 10,721,040.00 PLN.

\section{References}

Aarts, H., Verplanken, B., \& van Knippenberg, A. (1998). Predicting Behavior from Actions in the Past: Repeated Decision Making or a Matter of Habit? Journal of Applied Social Psychology, 28(15), 1355-1374. https:// doi.org/10.1111/j.1559-1816.1998.tb01681.x

Ajzen, I., \& Fishbein, M. (1980). Attitudes and Predicting Social Behavior. Englewood Cliffs, NJ: Prentice-Hall.

Alalwan, A. A., Dwivedi, Y. K., \& Rana, N. P. (2017). Factors influencing adoption of mobile banking by Jordanian bank customers: Extending UTAUT2 with trust. International Journal of Information Management, 37(3), 99-110. https://doi.org/10.1016/j.ijinfomgt.2017.01.002
Anderson, M. (2015). Technology Device Ownership: 2015. Pew Research Center. Retrieved July 20, 2020, from http://www. pewinternet.org/2015/10/29/technologydevice-ownership-2015

Blair, E., \& Blair, J. (2015). Applied Survey Sampling. New York, NY: SAGE Publications. https://doi.org/10.4135/9781483394022

Boot, A. W. (2017). The Future of Banking: From Scale \& Scope Economies to Fintech 29. European Economy, 3(2), 77-95.

Capgemini \& Efma. (2016). World Retail Banking Report 2016. Retrieved July 19, 2020, from https://worldretailbankingreport.com/ resources/world-retail-banking-report-2020/

Carlin, B., Olafsson, A., \& Pagel, M. (2017). Fintech Adoption across Generations: Financial Fitness in the Information Age (NBER Working Paper No. 23798). Cambridge, MA: National Bureau of Economic Research. https://doi. org/10.3386/w23798

Cognizant, Marketforce and Pegasystems. (2016). The Future of Retail Financial Services. Retrieved July 15, 2020, from https://www. pega.com/future-of-finance

Das, A., \& Das, D. (2020). Perception, Adoption, and Pattern of Usage of FinTech Services by Bank Customers: Evidences from Hojai District of Assam. Emerging Economy Studies, 6(1), 7-22. https://doi. org/10.1177\%2F2394901520907728

Davis, F. D. (1985). A technology acceptance model for empirically testing new end-user information systems: Theory and results (Doctoral dissertation). Massachusetts Institute of Technology, Cambridge. Retrieved July 19, 2020, from https://dspace.mit.edu/ handle/1721.1/15192

Davis, F. D. (1989). Perceived Usefulness, Perceived Ease of Use, and User Acceptance of Information Technology. MIS Quarterly, 13(3), 319-340. https://doi.org/10.2307/249008

Diana, N., \& Leon, F. M. (2020). Factors Affecting Continuance Intention of FinTech Payment among Millennials in Jakarta. European Journal of Business and Management Research, 5(4). https://doi.org/10.24018/ ejbmr.2020.5.4.444

Endsley, F., Matthews, L., \& Ward, C. (2020). An Analysis of Millennials and their Interactions with Financial Institutions. Atlantic Marketing Journal, 9(2), 1-18. Retrieved April 29, 2021, from https://digitalcommons.kennesaw.edu/ amj/vol9/iss $2 / 1$ 
Ernst \& Young. (2017). FinTech Adoption Index: FinTech services poised for mainstream adoption in the US with 1 in 3 digitally active consumers using FinTech. Retrieved July 20, 2020, from https://www.prnewswire.com/newsreleases/ey-fintech-adoption-index-fintechservices-poised-for-mainstream-adoption-inthe-us-with-1-in-3-digitally-active-consumersusing-fintech-300481126.html

Ernst \& Young. (2019). Global FinTech Adoption Index 2019. Retrieved August 6, 2020, from https://www.ey.com/en_gl/eyglobal-fintech-adoption-index

European Parliament. (2017). Report on FinTech: The influence of technology on the future of the financial sector (2016/2243(INI)). (EP Resolution adopted text P8_TA (2017)0211). Official Journal of the European Union, C 307/57. Retrieved July 19, 2020, from https://eur-lex.europa.eu/legal-content/EN/ TXT/PDF/?uri=CELEX:52017IP0211\&rid=1

Financial Stability Board. (2019). FinTech and market structure in financial services: Market developments and potential financial stability implications (Report). Retrieved July 25, 2020, from https://www.fsb.org/wp-content/ uploads/P140219.pdf

Flavián, C., Guinalíu, M., \& Torres, E. (2006). How bricks-and-mortar attributes affect online banking adoption. International Journal of Bank Marketing, 24(6), 406-423. https://doi. org/10.1108/02652320610701735

Gimpel, H., Rau, D., \& Röglinger, M. (2018). Understanding FinTech start-ups - a taxonomy of consumer-oriented service offerings. Electronic Markets, 28(3), 245-264. https://doi. org/10.1007/s12525-017-0275-0

Hosmer, D. W., \& Lemesbow, S. (1980). Goodness of fit tests for the multiple logistic regression model. Communications in Statistics - Theory and Methods, 9(10), 1043-1069. https://doi.org/10.1080/03610928008827941

Hu, Z., Ding, S., Li, S., Chen, L., \& Yang, S. (2019). Adoption Intention of Fintech Services for Bank Users: An Empirical Examination with an Extended Technology Acceptance Model. Symmetry, 11(3), 340. https://doi.org/10.3390/ sym 11030340

Huei, C. T., Cheng, L. S., Seong, L. C., Khin, A. A., \& Bin, R. L. L. (2018). Preliminary Study on Consumer Attitude towards FinTech Products and Services in Malaysia. International Journal of Engineering \& Technology, 7(2.29), 166-169. https://doi.org/10.14419/ijet.v7i2.29.13310
International Monetary Fund. (2018). The Bali Fintech Agenda (IMF Policy Paper 2018/050). Washington, DC: International Monetary Fund. https://doi.org/10.5089/9781498309950.007

Karahanna, E., \& Straub, D. W. (1999). The psychological origins of perceived usefulness and ease-of-use. Information \& Management, 35(4), 237-250. https://doi.org/10.1016/S03787206(98)00096-2

Kim, Y., Choi, J., Park, Y. J., \& Yeon, J. (2016). The adoption of mobile payment services for "Fintech". International Journal of Applied Engineering Research, 11(2), 1058-1061.

Koufaris, M. (2002). Applying the Technology Acceptance Model and Flow Theory to Online Consumer Behavior. Information Systems Research, 13(2), 205-223. https://doi. org/10.1287/isre.13.2.205.83

Kurek, R., Solarz, M., \& Swacha-Lech, M. (2020). The Problem of Millennials' Openness to Services Offered by FinTech in Poland. In K. S. Soliman (Ed.), Education Excellence and Innovation Management: A 2025 Vision to Sustain Economic Development during Global Challenges (pp. 11020-11033). Sevilla: International Business Information Management Association (IBIMA).

Lee, D. K. C., \& Teo, E. G. S. (2015). Emergence of FinTech and the LASIC Principles. Journal of Financial Perspectives, 3(3), 1-26. https://doi.org/10.2139/ssrn.2668049

Lee, K. W., Tsai, M. T., \& Lanting, M. C. L. (2011). From marketplace to marketspace: Investigating the consumer switch to online banking. Electronic Commerce Research and Applications, 10(1), 115-125. https://doi. org/10.1016/j.elerap.2010.08.005

Li, B., Hanna, S. D., \& Kim, K. T. (2020). Who Uses Mobile Payments: Fintech Potential in Users and Non-Users. Journal of Financial Counseling and Planning, 31(1), 83-100. https://doi.org/10.1891/JFCP-18-00083

Liébana-Cabanillas, F., SánchezFernández, J., \& Muñoz-Leiva, F. (2014). Antecedents of the adoption of the new mobile payment systems: The moderating effect of age. Computers in Human Behavior, 35, 464478. https://doi.org/10.1016/j.chb.2014.03.022

Lin, H. H., \& Wang, Y. S. (2006). An examination of the determinants of customer loyalty in mobile commerce contexts. Information \& Management, 43(3), 271-282. https://doi.org/10.1016/j.im.2005.08.001 
Mallat, N. (2007). Exploring consumer adoption of mobile payments - A qualitative study. The Journal of Strategic Information Systems, 16(4), 413-432. https://doi. org/10.1016/j.jsis.2007.08.001

Martins, C., Oliveira, T., \& Popovič, A. (2014). Understanding the Internet banking adoption: A unified theory of acceptance and use of technology and perceived risk application. International Journal of Information Management, 34(1), 1-13. https://doi. org/10.1016/j.jijinfomgt.2013.06.002

Montazemi, A. R., \& Qahri-Saremi, H. (2015). Factors affecting adoption of online banking: A meta-analytic structural equation modeling study. Information \& Management, 52(2), 210-226. https://doi.org/10.1016/j. im.2014.11.002

Morris, M. G., Venkatesh, V., \& Ackerman, P. L. (2005). Gender and age differences in employee decisions about new technology: An extension to the theory of planned behavior. IEEE Transactions on Engineering Management, 52(1), 69-84. https://doi. org/10.1109/TEM.2004.839967

Nangin, M. A., Barus, I. R. G., \& Wahyoedi, S. (2020). The Effects of Perceived Ease of Use, Security, and Promotion on Trust and Its Implications on Fintech Adoption. Journal of Consumer Sciences, 5(2), 124-138. https://doi. org/10.29244/jcs.5.2.124-138

Niswah, F. M., Mutmainah, L., \& Legowati, D. A. (2019). Muslim Millennial's Intention of Donating for Charity using Fintech Platform. Journal of Islamic Monetary Economics and Finance, 5(3), 623-644. https://doi. org/10.21098/jimf.v5i3.1080

OECD. (2018). Financial Markets, Insurance and Private Pensions: Digitalisation and Finance. Paris: OECD. Retrieved July 9, 2020, from https://www.oecd.org/finance/ private-pensions/Financial-markets-insurancepensions-digitalisation-and-finance.pdf

Park, I., \& Lee, H. (2006). Design Effects for the Weighted Mean and Total Estimators under Complex Survey Sampling. Quality Control and Applied Statistics, 51(4), 381-384.

Rai, A., \& Patnayakuni, R. (1996). A Structural Model for CASE Adoption Behavior. Journal of Management Information Systems, 13(2), 205-234. https://doi.org/10.1080/074212 22.1996.11518129

Rogers, E. M. (2010). Diffusion of Innovations (4th ed.). New York, NY: The Free Press.
Ryu, H. S. (2018). Understanding Benefit and Risk Framework of Fintech Adoption: Comparison of Early Adopters and Late Adopters. In Proceedings of the 51st Hawaii International Conference on System Sciences (pp. 3864-3873). Waikoloa Village, Hawaii. Retrieved July 29, 2020 , from https://scholarspace.manoa.hawaii. edu/bitstream/10125/50374/1/paper0487.pdf https://doi.org/10.24251/HICSS.2018.486

Solarz, M., \& Swacha-Lech, M. (2019). Mental accounting in the context of savings and credit decisions. Evidence from Poland. Argumenta Oeconomica, 2(43), 351-384. https://doi.org/10.15611/aoe.2019.2.15

Stewart, H., \& Jürjens, J. (2018). Data security and consumer trust in FinTech innovation in Germany. Information \& Computer Security, 26(1), 109-128. https://doi. org/10.1108/ICS-06-2017-0039

Swacha-Lech, M. (2017). The main challenges facing the retail banking industry in the era of digitalisation. Rozprawy Ubezpieczeniowe. Konsument na rynku usług finansowych, 4(26), 94-116. Retrieved August 16, 2020, from https://depot.ceon.pl/ handle/123456789/14336

Szopiński, T. S. (2016). Factors affecting the adoption of online banking in Poland. Journal of Business Research, 69(11), 4763-4768. https:// doi.org/10.1016/j.jbusres.2016.04.027

Tang, K. L., Ooi, C. K., \& Chong, J. B. (2020). Perceived Risk Factors Affect Intention to Use FinTech. Journal of Accounting and Finance in Emerging Economies, 6(2), 453-463. https://doi.org/10.26710/jafee.v6i2.1101

Venkatesh, V., \& Bala, H. (2008). Technology Acceptance Model 3 and a Research Agenda on Interventions. Decision Sciences, 39(2), 273-315. https://doi.org/10.1111/j.15405915.2008.00192.x

Venkatesh, V., \& Davis, F. D. (2000). A Theoretical Extension of the Technology Acceptance Model: Four Longitudinal Field Studies. Management Science, 46(2), 186-204. https://doi.org/10.1287/mnsc.46.2.186.11926

Venkatesh, V., Morris, M. G., Davis, G. B., \& Davis, F. D. (2003). User acceptance of information technology: Toward a unified view. MIS Quarterly, 27(3), 425-478. https://doi. org/10.2307/30036540

Venkatesh, V., Thong, J. Y., \& Xu, X. (2012). Consumer Acceptance and Use of Information Technology: Extending the Unified 


\section{Finance}

Theory of Acceptance and Use of Technology. MIS Quarterly, 36(1), 157-178. https://doi. org/10.2307/41410412

Wu, J. H., \& Wang, S. C. (2005). What drives mobile commerce? An empirical evaluation of the revised technology acceptance model. Information \& Management, 42(5), 719-729, https://doi.org/10.1016/j.im.2004.07.001

Yee, B. Y., \& Faziharudean, T. M. (2010). Factors Affecting Customer Loyalty of Using Internet Banking in Malaysia. Journal of Electronic Banking Systems, 2010(2010), ID 592297, 1-21. https://doi.org/10.5171/2010.592297
Yu, C. S. (2012). Factors affecting individuals to adopt mobile banking: Empirical evidence from the UTAUT model. Journal of Electronic Commerce Research, 13(2), 104-121. Retrieved July 20, 2020, from http:// www.jecr.org/node/48

Zavolokina, L., Dolata, M., \& Schwabe, G. (2016). FinTech - What's in a Name? Paper presented at the Thirty Seventh International Conference on Information Systems, Dublin, Ireland. https://doi.org/10.5167/uzh-126806 